\title{
CULTURA DE MASAS Y CULTURA AFIRMATIVA DENTRO DEL CONFLICTO INDIVIDUO Y SOCIEDAD. UNA APROXIMACIÓN DESDE LA TEORÍA CRÍTICA DE LA SOCIEDAD
}

Harold Valencia López Luis A. Zuñiga Herazo 


\title{
CULTURA DE MASAS Y CULTURA AFIRMATIVA DENTRO DEL CONFLICTO INDIVIDUO Y SOCIEDAD. UNA APROXIMACIÓN DESDE LA TEORÍA CRÍTICA DE LA SOCIEDAD*
}

\begin{abstract}
Resumen: El objetivo principal del siguiente trabajo es mostrar que el estudio de la cultura de masas realizado por la Escuela de Frankfurt permite analizar el conflicto individuo y sociedad desde una perspectiva distinta a la empleada por la tradición de la filosofía moderna, en especial, desde las llamadas teorías del contrato social. Para tal fin analizaremos, primero, la reformulación que Herbert Marcuse realiza del conflicto individuo y sociedad en la teoría de la cultura de Freud; luego, se estudiará la forma como la cultura de masas parece superar el conflicto, cuando consigue, aparentemente, una armonía entre el individuo y la sociedad. Cabe destacar que la hipótesis desarrollada es que Marcuse prefiere el conflicto individuo y sociedad a su aparente solución, pues, la existencia del conflicto mantiene al menos la conciencia de la escisión, condición para la preservación del pensamiento crítico de la sociedad.
\end{abstract}

Palabras clave: Sociedad, individuo, masa, cultura, conflicto.

\section{MASS CULTURE AND AFFIRMATIVE CULTURE WITHIN THE CONFLICT BETWEEN INDIVIDUALS AND SOCIETY. AN APROXIMATION FROM THE SOCIOCRITICAL THEORY}

\begin{abstract}
The main goal of this paper is to examine how the study of mass culture made by the Frankfurt School can analyze the conflict between individual and society, from a different perspective to that one studied by the tradition of modern philosophy, especially, from that called social contract theories. To achieve this objective we will, first, discuss the reformulation that Herbert Marcuse does about the conflict between individual and society, in the conflict culture theory of Freud; then, we will study how mass culture seems to overcome the conflict, when it, apparently has achieved a harmony between the individual and society. Our hypothesis is that Marcuse, ultimately, prefers to focus more on the conflict between individual and society than on its apparent solution. This is because, for him, the existence of the conflict maintains, at least, the conscious of the excision, a condition for the preservation of critical thinking in the society.
\end{abstract}

Keywords: Society, individual, mass culture, conflict.

Fecha de recepción: mayo 5 de 2014

Fecha de aceptación: febrero 24 de 2015

Forma de citar: Valencia, H. y Zuñiga, L. (2015). "Cultura de masas y cultura afirmativa dentro del conflicto individuo y sociedad. Una aproximación desde la teoría crítica de la sociedad". Revista Filosofía UIS. 14 (1). pp. 95-115.

Harold Valencia López: colombiano. Filósofo, Magíster y Doctor en filosofía de la Universidad Nacional de Colombia. Especialista en arbitraje, conciliación y resolución de conflictos de la Universidad de Cartagena. Profesor titular del Programa de Filosofía de la Universidad de Cartagena. Director del grupo de investigación en filosofía política y social "Civitas".

Correo electrónico: hvalencial@unicartagena.edu.co

Luis A. Zúñiga Herazo: colombiano. Magíster en Filosofía de la Universidad de los Andes. Profesor de tiempo completo del programa de Filosofía Universidad de Cartagena. Miembro del grupo de investigación "Civitas", reconocido por Colciencias.

Correo electrónico: zlha1973@hotmail.com

* Revisión de tema 


\section{CULTURA DE MASAS Y CULTURA AFIRMATIVA DENTRO DEL CONFLICTO INDIVIDUO Y SOCIEDAD. UNA APROXIMACIÓN DESDE LA TEORÍA CRÍTICA DE LA SOCIEDAD}

\section{Introducción}

El conflicto individuo y sociedad constituye uno de los temas clásicos de la filosofía moderna, en especial de los filósofos ${ }^{1}$ que consideraron la sociedad no como una necesidad originaria de los hombres, sino como el producto de un pacto o contrato entre individuos que, inicialmente, vivían aislados unos de otros. Dicho pacto buscaba, o bien superar (como lo sostenía Hobbes) la violencia y anarquía existente dentro del estado de naturaleza, o bien proteger (según Locke) la libertad civil y la propiedad, una vez que se iniciara algún conflicto que no se pudiera dirimir en el estado de naturaleza por la ausencia de jueces imparciales.

Más allá de las diferencias entre las teorías del contrato de Hobbes, Locke y Rousseau, acerca de las características propias del estado de naturaleza y las razones que daban origen al contrato social, coincidieron en que era necesario alcanzar una armonía entre los intereses de los individuos y los intereses sociales, entre la voluntad particular y la voluntad general, entre los ciudadanos y el Estado, que evitaba que los individuos entraran en situaciones de guerra de todos contra todos.

Así, Hobbes (1999) sostenía que, dada la escasez de recursos existentes en el medio, la condición antisocial y egoísta del individuo, la ausencia de normas y de instituciones que las hicieran cumplir, el estado de naturaleza no sería sino un estado de guerra de todos contra todos.

\footnotetext{
${ }^{1}$ Nos referimos especialmente a los Ilamados filósofos iusnaturalistas como Hobbes, Locke y Rousseau, que a pesar de sus diferencias respecto a lo que significa el estado de naturaleza, el contrato social y la sociedad civil, coinciden en ver la sociedad como algo contrario a la naturaleza humana.
} 
Al seguir esta concepción, se observa cómo el peligro de muerte en el que se encontraba el individuo en dicho estado constituía el impulso que lo llevaba a establecer acuerdos con los otros; así, el pacto o contrato donde éstos deponían su poder individual y se lo entregaban a una instancia superior, Leviatán o Estado, encargado de limitar los impulsos destructivos, aseguraba la paz y la vida de los miembros de la sociedad. En contraste, las condiciones anárquicas del estado de naturaleza serían sustituidas, tras el pacto o contrato, por el establecimiento de la vida en sociedad civil.

En contra de Hobbes, Locke (2006) negó que el estado de naturaleza fuera un estado de guerra; porque, si los hombres hacían uso de su razón no entraban en guerra unos con otros, pues, si el estado de naturaleza tenía su origen en la competencia de los individuos por alcanzar los bienes escasos, la razón les permitía comprender que el derecho de posesión sobre las cosas dependía de si ellas eran o no el resultado de su trabajo. En este sentido, Locke (2006) consideraba la ausencia de magistrados en el estado de naturaleza como el problema fundamental, debido a que no se podían dirimir los conflictos entre los hombres al convertirse ellos mismos en jueces de sus propias causas. De ahí que la ausencia de jueces imparciales constituya la causa de que los conflictos se desenvuelvan hasta convertir el estado de naturaleza en uno de guerra. En medio de todo, el contrato social permitía asegurar la paz entre los miembros de la sociedad, así como la creación de instancias jurídicas garantistas de la propiedad privada y la libertad.

Por su parte, Rousseau (1998) negó que la sociedad fuera la solución de nuestros males y, por el contrario, idealizó la condición de estado de naturaleza como aquella en la cual los hombres podían ser felices. El problema se inició, según él, con la aparición de la propiedad privada, cuyo desarrollo generó todo tipo de injusticias, desigualdades y conflictos. De ahí que el contrato social (Rousseau, 1998) debía asegurar la seguridad, la propiedad y la libertad; además, del estatus mínimo de igualdad entre los hombres. A través de la implantación de la voluntad general, que surgía tras los acuerdos alcanzados en el contrato social, se podían recoger y armonizar las diversas voluntades particulares y los respectivos intereses particulares de los miembros de la sociedad, en aras de un bien público que permitiese el vínculo y la convivencia social.

Cabe señalar que no es preciso realizar una exégesis o profundización sobre las características del conflicto entre el individuo y la sociedad en los filósofos del contrato en este trabajo; puesto que nos interesa mostrar que otra tradición del pensamiento filosófico, muy distante, incluso del liberalismo político (al que suele asociarse esa defensa del ámbito privado de la persona, a través de la necesidad de ponerle un límite a la injerencia que puede tener el Estado sobre el individuo), hizo suya esta defensa de la personalidad individual, motivada seguramente por el rechazo que le producía la forma como se habían destruido, hasta las últimas 
reservas, la autonomía y libertad personal en los regímenes totalitarios tanto de derecha como de izquierda existentes durante gran parte del siglo $\mathrm{XX}^{2}$. Por esta razón, nos referimos a la tradición filosófica conocida comúnmente con el nombre de Escuela de Frankfurt (también denominada Teoría crítica de la sociedad) a la que pertenecen pensadores representativos de la filosofía contemporánea del siglo XX como Max Horkheimer, Theodor Adorno y Herbert Marcuse, en su primera generación, y pensadores de la época actual como Jürgen Habermas, Albrecht Wellmer y Axel Honnett.

En el presente trabajo pretendemos resaltar cómo aspectos de la autonomía de la persona, donde se preservan las condiciones que hacen posible la existencia del pensamiento crítico, se diluyen en las formas cotidianas del consumo, en los hábitos y las costumbres de los sujetos y, en general, en las diversas manifestaciones de la cultura hegemónica de la sociedad de mercado, lo que genera un cierto déficit en las democracias liberales en detrimento del desarrollo de una auténtica autonomía de la persona. En dicho sentido, consideramos que la búsqueda de cohesión social entre el Estado y el ciudadano en la sociedad contemporánea, a través de la mediación ejercida por las industrias culturales, ha terminado por convertir a la cultura en cómplice del debilitamiento de la crítica, la ausencia de reflexión y el poco desarrollo del pensamiento autónomo.

De acuerdo con lo anterior, se busca establecer cuáles son las funciones cumplidas por las dos ideas predominantes de cultura (que a juicio de la Escuela de Frankfurt han existido en Occidente desde el siglo XVIII) en el intento de mediar en el conflicto entre individuo y sociedad. Las dos ideas de cultura son: la cultura afirmativa y la cultura de masas. Para ese fin mostraremos: primero, la forma como está planteado el conflicto individuo y sociedad en la teoría de la cultura de Freud, de quien heredó la Escuela de Frankfurt conceptos fundamentales para comprender los mecanismos de control y manipulación de masas. Entre ellos: represión, sublimación, introyección, psicología de las masas, entre otros.

\footnotetext{
${ }^{2}$ Tampoco es extraño que el conflicto individuo y sociedad sea un problema que se pueda encontrar en la filosofía de pensadores marxistas como Herbert Marcuse y Theodor Adorno. Es cierto que Marx reafirmó siempre la condición social de todo hombre, y cuestionó la atomización a la que nos llevaba el mercado y el mundo de los negocios de la sociedad capitalista; sin embargo, la adopción de un marxismo menos dogmático en que se incorporan los aportes de otras corrientes de pensamiento como el psicoanálisis freudiano, donde los problemas psíquicos del individuo, tienen, seguramente, más importancia que los problemas de la existencia social, permitió que corrientes marxistas como la Escuela de Frankfurt también mostraran preocupación por las problemáticas de la sociedad y el individuo.
} 


\section{Individuo y sociedad en Freud. La crisis de los conceptos del psicoanálisis según Herbert Marcuse}

Según la teoría de Freud (1997, pp. 217-235) en el individuo existen dos dimensiones caracterizadas por procesos mentales y principios diferentes. Principios diferentes que tienen dimensiones tanto genética-histórica como estructural. Así, el inconsciente regido por el principio del placer abarca los más antiguos procesos primarios, fragmentos de una fase de desarrollo en los que constituía la única clase de procesos mentales. Por su parte, el consciente se encarga de la adaptación del individuo a la realidad. De acuerdo con esto, las aspiraciones de goce provenientes del principio del placer entran en conflicto con el ambiente natural y humano y el individuo llega a la traumática comprensión de que la satisfacción completa, no es posible sin sufrimiento, de que la adaptación al mundo externo requiere de una dolorosa transformación de sus necesidades instintivas. Entonces, en ese proceso el individuo aprende a sustituir el placer momentáneo, incierto y destructivo, por el placer retardado, limitado, pero seguro. De este modo, se va instituyendo en el aparato mental un principio opuesto al principio del placer, denominado principio de realidad. A través de este, "el hombre desarrolla la función de la razón; aprende a tantear la realidad, y adquiere las facultades de atención, memoria y juicio (218).

El hecho de que el principio de realidad deba ser constantemente restablecido, evidencia que el triunfo sobre el principio del placer nunca es definitivo y absoluto. Más aun, originariamente, la adaptación del hombre al principio de realidad está basada en la promesa de que, a través de dicho principio, puede alcanzarse una gratificación más segura de sus necesidades instintivas. De ahí infiere Marcuse la tesis según la cual la civilización desarrolla en el individuo habilidades y capacidades que (la memoria, para citar un ejemplo) pueden ser potencialmente antagónicas a la civilización represiva; pues, si la adopción del principio de realidad es originada por la promesa de que es posible obtener, en el futuro, una satisfacción más segura que la alcanzada en los tiempos de dominio del principio del placer; entonces, en el inconsciente se conserva el deseo reprimido, así como en la memoria se mantiene la promesa de la cultura. Todas las restricciones impuestas por la cultura a los individuos mediante la represión de sus instintos, el dolor y el cansancio generado, históricamente, por las tareas del trabajo que sustentan el desarrollo y el progreso de la civilización, han estado fundadas en las expectativas de que, al final tales sacrificios, serán compensados con mayores posibilidades de gozo y satisfacción. Sin embargo, si la conclusión es como cree Freud: el progreso y desarrollo de la cultura se paga con el inevitable reconocimiento de que los individuos no pueden ser definitivamente felices dentro de la cultura, los sacrificios y sufrimientos realizados a favor de la misma se tornan, cada vez, más injustificados e innecesarios. Según Freud, esto explica que las masas se vuelvan ajenas y hostiles a cumplir las exigencias de la 
cultura, principalmente, en lo atinente a la realización de las tareas del trabajo y la inhibición de sus instintos (12). Se debe advertir que, si una sociedad ha renunciado a la posibilidad de gratificar a las grandes masas aunque éstas sean las creadoras con su trabajo de la riqueza existente, dicha sociedad se ve obligada a utilizar medios de represión adicional y diversas formas ideológicas para sostenerse legítimamente. En este orden de ideas, el gran logro de la sociedad industrial avanzada radica en la ampliación de las posibilidades de gratificación para las grandes masas, de modo que los individuos ya no parecen necesitar de la dolorosa y traumática transformación de sus instintos, enfrentándose a un mundo que no es esencialmente hostil, ni contrario a la gratificación de sus deseos.

En su intento de aplicar las categorías freudianas, desde una dimensión socio-histórica, Marcuse terminó por ir más allá del pensamiento de Freud; pues, los dos conceptos básicos de la teoría freudiana: el principio de realidad y el concepto de represión adquieren, tras la historización realizada en Eros y civilización (2003), los nombres específicos de principio de actuación y plus-represión o represión excedente; ${ }^{3}$ es decir, los modos característicos del principio de realidad y del concepto de represión de la sociedad industrial avanzada. Marcuse irá aún más lejos que Freud cuando introduce el concepto de desublimación-represiva. Al respecto cabe precisar que Freud habló siempre de sublimación ${ }^{4}$, no de desublimación-represiva, este

\footnotetext{
Marcuse distingue la represión básica de una sociedad y la denomina represión excedente. La represión básica hace referencia a los controles que una sociedad necesita para su propia conservación. Por ejemplo, la sublimación de las pulsiones sexuales; pero, sobre todo, las pulsiones de agresión limitan y orientan las reservas de energía de dichas pulsiones hacía fines distintos. Esto garantiza la convivencia entre un mayor número de hombres, así como facilita el propio desarrollo de la cultura; pues, las reservas de energía de tales pulsiones son transferidas a través de los diversos procesos de sublimación a las variadas actividades del trabajo, la creación artística y la investigación científica. En cambio, la represión excedente constituye las formas adicionales de represión que una sociedad ejerce sobre sus miembros. Así, la utilización de la violencia, las limitaciones a la autonomía de la persona y el control del tiempo libre son formas de represión excedente. Por ende, Marcuse sostiene que la represión es, también, un concepto histórico en tanto los niveles de control que una sociedad necesita para conservarse están sujetos al grado de desarrollo de la técnica y la ciencia, el desarrollo de la industrial y, en general, al menor o mayor desarrollo alcanzado de cultura material. Por ello, si la sociedad industrial avanzada tiene mayor grado de represión excedente es, precisamente, porque ha alcanzado, según Marcuse, un nivel de desarrollo en su cultura material que haría innecesaria la existencia de formas de control por ejemplo, la utilización de gran parte del tiempo en las actividades del trabajo enajenado; o formas de represión susceptibles de eliminarse con su capacidades técnicas, entre ellas, el hambre y la miseria en tres cuartas partes de la población mundial (Marcuse, 1995).

${ }^{4}$ Freud (1997, p.79) entiende por sublimación la desviación de energía erótica o la libido hacia fines diferentes a la meta de satisfacción originaria, esto es, no dirigida a la gratificación inmediata y directa de las pulsiones, sino hacia su satisfacción mediata a través de la alegría alcanzada en la creación artística y el placer obtenido en los logros
} 
último concepto se refiere al modo en que la sociedad avanzada puede, a través de procesos de liberación controlada, movilizar y administrar metódicamente los elementos explosivos y antisociales del inconsciente. En consecuencia, la desublimación represiva permite afianzar el dominio y el control que la sociedad tiene sobre el ámbito interior del ser humano.

Para Marcuse, los intereses de los individuos alcanzan un nivel de coincidencia y armonía con los intereses generales, a tal punto que no se puede hablar en los procesos de socialización de un proceso psico-social como la introyección. Pues este concepto freudiano supone la existencia de una dimensión interior separada y hasta antagónica de la sociedad, un inconsciente individual lejano de la sociedad. Esa dimensión interior del ser humano ha sido cercenada con la penetración de la sociedad a la alcoba y la disolución del pensamiento individual bajo la llamada opinión pública. La sociedad como totalidad termina destruyendo los espacios necesarios para la elaboración del pensamiento autónomo. Éstos se caracterizan, principalmente, porque el individuo puede obtener de ellos la soledad y el silencio, concebidas como condiciones mínimas para la independencia del individuo de la sociedad. Tales espacios son limitados ahora por el desarrollo de los medios de comunicación de masas y las características propias de la vida urbana, caracterizada por la masificación de las viviendas y los medios de trasporte, así como por el incremento masivo de los centros de consumo.

Esta socialización del ambiente, independiente a la penetración del sistema social, genera un incremento del dominio y el control ejercido por la sociedad sobre el individuo. Ahora, él se encuentra a merced del influjo, por decir menos, del poder de la sociedad de masas. Para Marcuse este proceso tiene unas consecuencias a nivel de la explicación de la teoría psicoanalítica, pues sus conceptos fundamentales, provenientes de la llamada estructura psíquica, se tornan caducos para poder explicar el conflicto individuo y sociedad. Expliquemos esto con más detalle: Marcuse afirma que el conflicto fatal entre el individuo y la sociedad en la teoría de Freud, se desarrolla inicialmente en la confrontación del niño y el adolescente con el padre. Este último (el padre) se encarga de asegurar la subordinación del principio del placer al principio de realidad, pues el proceso

de la ciencia y las diversas actividades de la cultura. Entonces, para Marcuse (1995) la desublimación sería la satisfacción mediata y directa de las pulsiones; sin embargo, en tanto dicha satisfacción se limite por las restricciones del espacio (destrucción y conquista técnica de los valles y los bosques, las praderas y las montañas, los ríos y los mares) y el tiempo libre (reducido cada vez más en la sociedades de masas a tiempo de trabajo, tiempo de transporte y tiempo de consumo) en las que el individuo podría obtener placer, pasa a ser una satisfacción orientada por el principio de realidad de la sociedad desarrollada. Por esta razón, esa desublimación termina siendo una liberación de las pulsiones sin libertad. Esto se puede pensar hoy bajo las formas sublimadas anteriores de gozo y placer de las diversas actividades humanas que contenían mayor grado de libertad, que las formas desublimadas de nuestros días. 
de adaptación y sometimiento del infante a las normas sociales depende primero de la labor activa que cumple la familia en el proceso de socialización. Y por eso, más allá del grado de autonomía que hubiera en la Familia su Yo se desarrollaba en antagonismo con las exigencias sociales que la familia representaba (Marcuse, 1974, p.14). Marcuse se refiere aquí a la concepción de Freud, que considera el desarrollo de la civilización como un proceso ontogenético, que se repite en cada individuo y, a partir del cual, éste deja de gratificar los deseos y pretensiones del principio del placer (con ciertos traumatismos) para someterse a las normas y reglas impuestas por el principio de realidad. El desarrollo del Superyó o internalización de las normas y las prohibiciones sociales, junto con la experiencia infantil del complejo de Edipo (como la primera renuncia realizada por el niño), repetiría en el individuo la historia del desarrollo de la civilización. De este modo, se implanta en la infancia del individuo los primeros tabúes, de manera similar a la instauración del tabú en la civilización, efectos del parricidio, la primera prohibición cultural de no matarás.

Una perspectiva distinta se analiza en el ensayo de Marcuse: El envejecimiento del psicoanálisis (1974). En este ensayo, el autor entiende por "envejecimiento del psicoanálisis" el carácter caduco de la explicación psicoanalítica de la formación del individuo y su personalidad a partir de la llamada estructura psíquica. Para Marcuse dicha estructura requiere ser modificada en la medida en que en la sociedad industrial avanzada se presenta un debilitamiento y empobrecimiento del Yo, quien se halla a merced de los deseos y las aspiraciones del Ello, junto a los mandamientos sociales de un Superyó cada vez más fortalecido. Los mandamientos de este último tienen menos la forma de prohibiciones morales (que anotamos se debilitan en esta sociedad) y mucho más las de patrones de comportamientos impuestos por la cultura de masas sobre los individuos. Patrones de comportamiento determinados, principalmente, por las formas de consumo y el modo en que deben utilizar los individuos el tiempo de ocio.

Asimismo, el empobrecimiento del Yo obedece a los cambios en los procesos de socialización de los individuos (Marcuse, 1974, p. 13), los cuales son efectuados por la sociedad de manera más inmediata y directa. Por ello, la labor de adaptación y sumisión del individuo a la sociedad se realiza en forma más inmediata y temprana, si se observa que ésta penetra en el individuo antes de su desarrollo como persona, de modo que los procesos de internalización de las normas y las prohibiciones comienzan en un tiempo en el que el Yo todavía no está formado completamente. Igualmente, los medios de comunicación masiva y los aparatos técnicos de uso doméstico sustituyen la labor que la familia lleva a cabo en etapas de menor desarrollo material de la cultura. La pérdida de autoridad del padre con los procesos inmediatos de socialización se agudiza, según Marcuse, con las crisis de la empresa familiar de las capas medias de la población, en la medida en que los hijos ganan con la desaparición de aquella mayor independencia en la elección de sus profesiones, "búsqueda de empleo y 
formas de ganarse la vida" (14). A esta crisis de la función del padre y de la familia en el proceso de socialización, deberíamos agregar la inserción, cada vez mayor, de la mujer en el mercado laboral (algo que Marcuse no tiene en cuenta).

Esta transformación de los procesos de socialización implica un distanciamiento de Marcuse de la teoría de Freud, más allá de lo que él mismo reconoce. Ya que si Marcuse desarrolla su análisis dentro de los conceptos de la llamada estructura psíquica, al introducirlos en un marco socio histórico, como el de la sociedad industrial avanzada, éstos conceptos aparecen con un significado diferente al que tenían en el psicoanálisis de Freud. Por ejemplo, el concepto de Superyó estaría representado menos por los padres, y más por el papel de los niños en la socialización, los medios de comunicación, los juegos de video y los clubes deportivos. Como éstos realizan los procesos de socialización prescindiendo de los residuos de arbitrariedad y violencia presentes en la formación de los padres sobre sus hijos, la socialización se torna para los niños y jóvenes menos dolorosa y traumática. Sin embargo, Marcuse cree que esta mayor libertad del niño y el joven dentro de la familia no implica un aumento de su autonomía, por esta razón afirma:

Paradójicamente, parece que la libertad que habían disfrutado en una familia ampliamente desprovista de autoridad, es más un abandono que una bendición: el yo que se había desarrollado sin grandes conflictos aparece como una entidad bastante débil, al punto de convertirse en un ego con los demás y contra ellos, de oponer una resistencia eficaz a los poderes que imponen en la actualidad el respeto por el principio de realidad y que difieren enormemente del padre (y de la madre), de las imágenes rectoras que presentan los medios de comunicación de masas (19).

Del pasaje reproducido, podemos inferir que Marcuse creía, con cierta preferencia, en la permanencia del conflicto entre individuo y sociedad; además, considera la aparente armonía existente entre ellos en el capitalismo tardío. Armonía que es en realidad falsa, pues se sostiene sobre la base de un debilitamiento de las capacidades críticas y de la conciencia moral.

Por otra parte, debemos señalar que en el psicoanálisis se mantiene una discrepancia interna entre los elementos críticos de la teoría y los aspectos conservadores de la terapia. Así, mientras la teoría reconoce que la enfermedad del individuo es generada y mantenida por la enfermedad de la sociedad, en general, la terapia psicoanalítica aspira a curar al individuo para que continúe siendo funcional a la sociedad. Según Marcuse, en la teoría de Freud, el pasado sobrevive en el inconsciente a través de los deseos que han sido reprimidos en la infancia del individuo (ontogénesis) y en los inicios de la prehistoria del género (filogénesis); por eso, el Yo debe luchar contra ese pasado que amenaza a la propia conservación de la civilización con sus pretensiones de satisfacción. 
Teóricamente, para el psicoanálisis, la diferencia entre una persona sana y un enfermo mental con neurosis o psicosis radica en la menor capacidad de una persona enferma para renunciar al principio del placer y adaptarse al principio de realidad. Es decir, la persona mentalmente sana renuncia más eficientemente a no poder satisfacer las exigencias del principio del placer y aceptar, por tanto, las tareas y mandatos del principio de realidad; porque, comprende más los riesgos culturales implicados en negarse a cumplir dichas exigencias.

En ese sentido, la neurosis y la psicosis constituyen expresiones de la rebeldía del Ello contra el mundo exterior. Tales enfermedades necesitan ser curadas, porque, están en contradicción con el buen funcionamiento de la sociedad. Pero si la cura implica una renuncia a la posibilidad de gratificar las aspiraciones más antiguas del principio del placer, el funcionamiento correcto de la sociedad está sujeto, en última instancia, a la represión e infelicidad del individuo.

Aunque la teoría psicoanalítica considera que la causa del conflicto entre el individuo y la sociedad tiene su origen en la incapacidad de esta última para satisfacer las aspiraciones de gratificación de los individuos, la práctica de la terapia termina adjudicándoles sólo el problema a los individuos. Si se sostiene que ellos son los que se encuentran enfermos, y son ellos los que deben adaptarse a una sociedad que, a pesar de sus problemas, es más o menos sana.

En otro momento, Marcuse (1979) considera que no es el individuo el que está enfermo sino la sociedad; porque, existe una discrepancia entre las capacidades técnicas amplias que esta posee para gratificar las necesidades humanas y disminuir en gran medida las restricciones impuestas sobre la vida instintiva de los individuos y la represión excedente, ejercida contra las posibilidades de liberación instintiva y la gratificación de esas necesidades. Es cierto que la teoría psicoanalítica contempla que, debido a esa insatisfacción de las necesidades y los instintos humanos, el conflicto entre el individuo y la sociedad tiene un carácter irresoluble; pero, si la sociedad avanzada tiene la capacidad técnica para resolver las causas de ese conflicto y no lo hace, los problemas psicológicos de algunos hombres no podrían reducirse simplemente a la adaptación de éstos a su medio, sino que es preciso transformar el medio social donde viven los "hombres enfermos".

Mientras esto sucede, Marcuse considera necesario hacer una inversión en las nociones de individuo sano y enfermo, pues si se acepta que la sociedad se encuentra enferma; entonces, el individuo sano no puede ser quien se adapta y se conforma a ella (1979, p.103), sino, precisamente, es quien no se resigna y no se integra; en otras palabras, es quien no está dispuesto a seguir con el juego. Marcuse prefiere (mientras se mantenga la plus represión en la sociedad avanzada) hacer una defensa del conflicto individuo y sociedad, tal como se desarrolla en la teoría de Freud, que aceptar la falsa reconciliación presente en el capitalismo 
industrial avanzado entre lo particular y lo general, lo singular y lo universal, el individuo y la sociedad.

\section{Cultura afirmativa y cultura de masas}

Para avanzar en el análisis de las diferencias entre la cultura afirmativa y la cultura de masas, nos apoyaremos, en los planteamientos expuestos por Herbert Marcuse, además, en los estudios de Theodor Adorno, otro miembro de la Escuela de Frankfurt ${ }^{5}$. El propósito es mostrar que, en comparación con la cultura afirmativa, la cultura de masas se vuelve mucho más funcional frente a los procesos de integración del individuo y la sociedad.

Así, desde Marcuse, se entiende por cultura afirmativa, aquella cultura esencialmente idealista, predominante durante los siglos XVIII y XIX. En dicha cultura los valores éticos, estéticos y religiosos constitutivos del ámbito espiritual humano se realizan sólo en las dimensiones internas del alma y de la interioridad humana, o se mantienen como anhelos y aspiraciones sólo posibles en un más allá de este mundo. En esta cultura se separan los ideales del arte, la filosofía y la religión de la esfera del trabajo y los negocios; en esa separación los ideales se preservan como expresiones humanas más elevadas y dignas de los hombres y como parte de un orden diferente al mundo de los negocios y el trabajo. Aunque Marcuse considera que esta cultura afirmativa predominó en la sociedad burguesa durante los siglos XVIII y XIX, ${ }^{6}$ no olvida que su origen teórico procede de los propios clásicos de la filosofía griega, quienes deslindaron el ámbito de lo necesario y funcional (asociado al mundo del esfuerzo y el sacrificio del trabajo) de la esfera de lo bello y verdadero (asociada al mundo del arte, la ciencia y la filosofía). Asimismo, al defender Platón y Aristóteles la postura según la cual las

\footnotetext{
${ }^{5}$ Por Escuela de Frankfurt entendemos una tradición de pensamiento filosófico, entre cuyos representantes se encuentran: Max Horkheimer, Theodor Adorno y Herbert Marcuse. Cabe indicar que están influenciados por la filosofía de Marx, Freud y, en menor medida, la filosofía de Kant, Hegel y Nietzsche, la sociología de Max Weber; en general, otras corrientes del pensamiento desarrolladas en las ciencias sociales. La complejidad de los temas tratados hacen muy difícil sintetizar las características de su filosofía social, sin embargo, nos atreveríamos a decir que la condición de dialéctica negativa de su filosofía, el carácter crítico de la teoría, los aspectos interdisciplinarios en sus estudios y su debate contra el método positivista serían los aspectos más destacados en las concepciones adelantadas por sus miembros.

${ }^{6}$ En los trabajos de Alicia Entel (2001) y de Blanca Muñoz (2000) se descuidan las diferencias entre la cultura afirmativa y la cultura de masas, al no distinguir que en los siglos XVIII y XIX la cultura afirmativa era la forma característica de la cultura burguesa; mientras que en el siglo XX y en la época actual, la cultura de masas es la forma característica de la cultura en la sociedad capitalista. De acuerdo con esto, en la medida en que la primera generación de la Escuela de Frankfurt ha desarrollado su filosofía en el siglo XX, se podría decir que su análisis se ha dirigido más hacía la cultura de masa que a la llamada cultura afirmativa.
} 
funciones dentro del Estado debían estar organizadas acorde con los talentos innatos y las capacidades aprendidas de sus miembros, consideraron necesario separar el trabajo teórico de las labores prácticas asociadas a las necesidades de los habitantes de la pólis. En esta concepción aristocrática de la cultura se encontraba implícita la idea de que los hombres que estuvieran dedicados a una vida de esfuerzo y fatiga, sin satisfacer nunca sus necesidades por completo, estaban excluidos del reino de lo verdadero, el bien y la belleza.

Ahora bien, por cultura de masas Adorno entiende la reproducción y difusión masiva (desde la segunda mitad del siglo XX) de diversas expresiones de la cultura occidental. Si en los siglos XVIII y XIX esos procesos de reproducción y difusión de la cultura se habían desarrollado a través de medios escritos como la prensa, los boletines, los folletos y los pasquines, siendo controlados en general por los grupos hegemónicos, pues esos medios no tenían en su distribución la capacidad de alcanzar a todos los grupos de la sociedad, desde finales del siglo XIX y comienzos del siglo XX los procesos de reproducción técnica incorporaron otros medios con capacidades masivas de difusión cultural como la radio y la televisión. Estos acontecimientos conducen a formular el siguiente interrogante: ¿Qué importancia tendrían estos medios en los procesos de integración entre el individuo y la sociedad? La respuesta aparentemente obvia sería que los medios han cumplido desde sus inicios un papel decisivo en los procesos de difusión y reproducción ideológica. Como se puede ver en La ideología alemana de Marx señalaba la importancia que tendría los medios de reproducción de la cultura para la conservación del poder de la respectiva clase dominante (Marx, 2008, p. 58).

Aunque el control de los medios ha sido ciertamente potestad de los grupos dominantes de la sociedad, no se puede desconocer el papel que cumplieron en los procesos de emancipación que tuvieron lugar en Europa y las luchas de independencia en América en los siglos XVIII y XIX. A través de los folletos y pasquines se divulgaron gran parte de las ideas que sirvieron de estímulo a esos procesos revolucionarios; también, se configuraron los procedimientos y planes de acción que orientaban esas luchas ${ }^{7}$. Pensemos nada más en la incidencia que tendría en nuestro contexto (y en otras colonias americanas) la traducción de los derechos humanos realizada por Antonio Nariño, así como la divulgación de otros documentos escritos que servían en ese momento de conspiración contra tales regímenes injustos.

Una idea más amplia en este sentido la podemos encontrar en Franzo Xabier Guerra (1992), quien sostiene la tesis de que las luchas de independencia en América latina estuvieron orientadas, como las revoluciones en Europa, por la difusión de las ideas ilustradas. Estas se difundieron más fácilmente tanto por la presencia de medios escritos como los pasquines, los folletos, manuales y boletines, como por la aparición de ciertos espacios de sociabilidad entre los que destaca los cafés y las tabernas. 
Por otra parte, la importancia de la escritura en los procesos de emancipación se confirmaba con lo expresado por un filósofo tan representativo de la época como Immanuel Kant, quien afirmaba que la única condición exigida para alcanzar la ilustración, es decir, para pensar por sí mismo sin la necesidad de un tutor o guía, era el uso público de la propia razón, en otras palabras, era el uso "que alguien hacía de ella en cuanto sabio ante la totalidad del público lector" (1986, p. 33). De acuerdo con esto, Kant consideraba indispensable que las personas pudieran hacer uso de su propio entendimiento, que tuvieran la libertad de expresar sus puntos de vista sobre temas de interés para toda una comunidad; simultáneamente, que tuvieran acceso a las reflexiones producidas por los sabios en otros temas. Entonces, se tenía la confianza plena de que, junto a la lectura de los libros, periódicos y revistas, así como el acceso, en general, a la información, se iban a crear las condiciones propicias para garantizar la posibilidad de emancipación y liberación de los individuos de aquellos regímenes despóticos y autoritarios.

Adviértase que, La dialéctica de la ilustración de Adorno y Horkheimer, analiza las razones por las cuales la ciencia y la técnica ${ }^{8}$ terminarían por cumplir unos fines distintos a aquellos para los que habían sido creadas; además, muestra en su análisis, por qué las publicaciones de periódicos, revistas y folletines, ya no estaban orientadas a contribuir a un proceso de ilustración. Para Adorno y Horkheimer era claro que, en el siglo XX, la información divulgada a través de dichos medios no contribuía ${ }^{9}$ a configurar un orden basado más en la razón que en la fe religiosa; por esa razón, al no ser capaz de incidir en el derrumbe de los mitos y falsas creencias, tampoco ayudaba a la formación de un pensamiento crítico y autónomo. En contraste, se observa que la producción y distribución

\footnotetext{
${ }^{8}$ El pensamiento filosófico de la ilustración confiaba plenamente en que el dominio de la ciencia y la técnica permitiría la liberación de las ilusiones, los mitos y los fantasmas, haciendo más libres sus relaciones como seres genéricos y sus relaciones con la naturaleza. Sin embargo, como ese dominio y control sobre la naturaleza estaba basado, principalmente, en el trabajo humano, las disposiciones metódicas de la ciencia y la técnica terminaron ciertamente quitándoles el poder divino y misterioso a los fenómenos naturales, al costo de ejercer, por medio del trabajo, un dominio sobre la mayoría de los hombres. Así, aquellas disposiciones técnicas penetraron sobre la naturaleza, también, sobre todas las dimensiones de la existencia humana. En última instancia, el hombre logró despojarse de los mitos religiosos con la ilustración; pero, sobre la base de construir un nuevo mito, esto es, la creencia de que los progresos de la ciencia y la técnica iban a conducir a los hombres a desarrollar una vida dentro de una sociedad más racional. Para una ampliación de esta tesis se recomienda ver Horkheimer y Adorno (1969a).

${ }^{9}$ Adorno advierte nuevas formas de superstición y difusión del pensamiento irracional en los periódicos y en las "páginas sociales" que se refieren a temas ligeros como el horóscopo, las cartas astrales y los libros de superación personal. Esta metafísica popular está dirigida, paradójicamente, a un público de clase media que ha tenido acceso al conocimiento y que "sabe cómo es el mundo". Para una ampliación de este tema revisar los planteamientos de Adorno (1972).
} 
en masa de revistas, periódicos y libros, actúa en contra de la capacidad del individuo para elaborar un proceso de reflexión y análisis sin la predeterminación de los medios de formación de la opinión al servicio de los intereses de los grupos sociales dominantes.

Ahora bien, como el texto escrito era el medio característico de difusión de las ideas, en los siglos XVIII y XIX, la única vía de recepción era la lectura, todavía inaccesible, en la época, a un público mayoritariamente iletrado. En la medida en que los medios escritos son sustituidos por medios como la televisión; los discursos escritos de periódicos, revistas, folletos, folletines y pasquines terminan siendo reemplazados por el discurso oral y la capacidad de representación mental de lo leído por el contenido explícito de las imágenes, éstas logran penetrar, incluso, sobre aquel público que aun se sustraía de la lectura. Por ello, no parece posible que los individuos en la época actual puedan escapar a su poder, ni siquiera en los países subdesarrollados donde este tipo de aparatos de uso doméstico tienden cada vez más a disminuir sus costos.

Adorno sostiene que la radio, la televisión y la prensa están articuladas con la totalidad del sistema capitalista, al punto de considerarlas integradas, junto con el cine, en lo que denomina comolas industrias culturales. Para Adorno la dependencia recíproca entre dichas industrias culturales, de otras formas de industrias como los textiles, el petróleo, la energía y las empresas de servicios públicos ${ }^{10}$, hacen que en la sociedad industrial avanzada ya no se pueda presentar a la superestructura cultural como una esfera separada de la infraestructura económica (1967, p. 35). Pues si bien los objetivos principales de las industrias culturales pueden trascender al lucro, las ganancias y el interés que acompañan a las actividades productivas de otras industrias, ellas configuran toda una estructura técnica a través de la cual los grupos dominantes difunden y reproducen sus valores e ideales, sin que éstos se vean trastocados o amenazados por el público sobre el cual se divulgan. Dicha ganancia, interés y lucro pueden estar subordinados a la ideología difundida a través de la industria cultural, porque las capacidades del sistema son de tal magnitud que pueden gastar gran cantidad de recursos en publicidad, derrochar en forma planificada y producir bienes y servicios improductivos y obsolescencias.

Para Adorno, el hiperconsumo de la información en las sociedades contemporáneas sería dentro de esa dialéctica de la ilustración contrario a los procesos de emancipación, de desarrollo de actitud analítica y reflexiva de los individuos. En ese sentido el establecimiento del pensamiento autónomo

\footnotetext{
${ }^{10}$ La televisión, la radio y el Internet se convierten en las mediaciones entre lo que la industria capitalista produce y aquello que, supuestamente, los consumidores demandan; en esa mediación, los medios de comunicación, a través de la publicidad, estimulan, promueven e imponen hábitos de consumo, según evidencian las ganancias alcanzadas con esa publicidad; sin embargo, de la dependencia recíproca de esta industria cultural de estas otras industrias.
} 
dependerá paradójicamente de la posibilidad de que el individuo tenga un mayor tiempo libre alejado de dichos medios de comunicación. Este análisis de Adorno también es compartido por Marcuse y los otros miembros de la primera generación de la escuela de Frankfurt. Marcuse afirma que la sola idea de que el individuo pudiera contenerse a su deseo de estar informado y entretenido puede ser considerada, por sí misma, como una idea de liberación catastrófica, pues la radio, la prensa y en especial la televisión, se han convertido en necesidades humanas de una importancia sólo comparables con las necesidades orgánicas. Marcuse anota:

La mera supresión de todo tipo de anuncios y adoctrinamiento de información y diversión sumergiría al individuo en un vacío traumático en el que tendría la oportunidad de sorprenderse y pensar, de conocerse a sí mismo y a su sociedad. [...] Sin duda tal situación sería una pesadilla intolerable. Aunque la gente puede soportar la continua creación de armas nucleares, de lluvias radioactivas y comidas dudosas (por esta misma razón) no puede tolerar que se le prive de las diversiones y la educación que los hace capaces para reproducir las disposiciones para su defensa o su destrucción (1995, p 124).

En contraste con los planteamientos de la primera generación de la Escuela de Frankfurt, Jürgen Habermas asume una posición considerada optimista frente a las contribuciones que los medios pueden realizar en los procesos de democratización de la sociedad. Por ello, para Habermas los medios de comunicación permiten a los ciudadanos la posibilidad de ejercer un mayor control sobre las gestiones de sus gobernantes y del Estado, en general, garantizándole tanto a quienes viven en un ámbito urbano como en uno rural un mayor conocimiento sobre los derechos contemplados en las constituciones de sus respectivos países, así como el conocimiento de los procedimientos que han de seguir para hacerlos cumplir. Así mismo, con unos costos económicos muy bajos contribuyen a la educación, formación cultural y entretenimiento de las personas, siendo asequibles a todo público.

Al lado de lo expuesto, carece de sentido negar hoy la influencia de los medios vistos desde su potencial de crítica de la sociedad. Esta característica de los medios fue reconocida por Adorno, ciertamente, en los medios escritos desarrollados en los siglos XVIII y XIX; sin embargo, no es fácil aceptar hoy que los medios en sí mismos cumplan el propósito atribuido por Habermas en las "sociedades democráticas" actuales. 
Un análisis más amplio del tema ${ }^{11}$ se encuentra fuera de los alcances de este trabajo. No obstante, se puede advertir que hoy se mantiene y, probablemente, se ha incrementado el poder de seducción sobre los individuos, de los nuevos aparatos de comunicación (computadores personales, celulares "inteligentes", tabletas, etc.). En países como el nuestro donde se está muy lejos de un desarrollo de la ciencia y la técnica, además, donde prevalecen condiciones muy precarias respecto a las obras de infraestructura: carreteras, puentes y sistemas de servicios públicos, las telecomunicaciones avanzan a un nivel de desarrollo cuyos resultados contrastan notoriamente con la gratificación de tales necesidades. Eso significa que, así como el mayor consumo de medios no garantiza la ilustración de las personas, tampoco su acceso masivo se convierte en señal clara de mejores niveles de bienestar, pues más allá de la facilidad con que las personas en sociedades no desarrolladas adquieren los diversos bienes culturales, es claro que las desigualdades sociales y económicas no sólo persisten, sino que, incluso, se han agudizado. Por ello, la masificación de los productos culturales no puede entenderse en tal caso como un proceso de igualdad social de los hombres, sino como la forma en la cual los diversos grupos sociales son susceptibles de ser igualmente sometidos a las mismas formas de control y dominio.

De lo expuesto, señalamos dos importantes diferencias entre la cultura afirmativa y la cultura de masas. La primera es que la separación realizada entre la vida espiritual y la realidad material en la cultura afirmativa permitía que otras dimensiones de la vida humana como el arte, la política y la religión quedaran distantes de la lógica de los negocios y el comercio, ya que en la cultura de masas se disuelven esas diferencias al quedar sometidas tales dimensiones de la vida humana igualmente a los dominios del interés y el lucro. La segunda diferencia establece que, mientras la cultura afirmativa contribuía con sus concepciones idealistas de la felicidad, la belleza, el bien y la justicia a trascender teóricamente las tensiones y contradicciones de la infraestructura económica capitalista, la cultura de masas pretende integrar esos ideales como bienes de cualquier índole susceptibles de ser vendidos en el mercado. ${ }^{12}$ En esa integración se erosionan los ideales y las diversas esferas sociales que los defienden: los partidos políticos, la familia, la religión y la escuela.

\footnotetext{
${ }^{11}$ Un análisis crítico del optimismo de Habermas frente a la función de democratización de los medios lo podemos encontrar en el trabajo de Pablo Blesa, "Medios de comunicación y democracia". Ver: (Blesa, 2006).

${ }^{12}$ Para muchos el mercado capitalista puede vender buena calidad de vida, asociada a las comodidades de un lujoso apartamento, vehículo, áreas deportivas, espacios de recreación, oportunidades para estudiar, prolongar la vida y la juventud más allá de lo que la fantasía podía imaginar, gozar de unas vacaciones en lugares desconocidos y exóticos, etc.
} 


\section{Conclusión}

Hemos sostenido que una característica de la cultura afirmativa fue el carácter idealista que adquirió tanto la producción como el gozo universal de la cultura.

Señalamos, en cambio, que la producción y el gozo de los bienes culturales por las grandes masas se habían convertido, dentro de la cultura de masas de los países desarrollados, en una posibilidad real. Sin embargo, el carácter más real de la universalidad de esta cultura de masas no indica que hoy tengamos más sociedad.

Como se pudo apreciar, el consumo masivo de televisión, radio, telefonía celular e internet, la asistencia a escenarios deportivos, a los conciertos, a los centros comerciales no ha permitido ampliar y consolidar el tejido social; por el contrario, la afluencia de los individuos a esas industrias culturales y al consumo de sus productos, que aparecen ahora como las nuevas formas de identificación entre los hombres, como las nuevas formas de sociabilidad ${ }^{13}$ en la sociedad contemporánea, son causa y consecuencia de la crisis y disolución, aun mayor, de formas de sociabilidad. Entre las que cabe destacar, la disolución de programas e ideologías en los partidos políticos, descomposición de los procesos de identificación en la familia, atomización en el trabajo y la escuela, disolución de las tradiciones y costumbres de los habitantes que hacen parte de un mismo contexto histórico-social. Lo anterior conlleva a que las formas de "identificación" creadas por el consumo se encuentran cimentadas sobre bases superfluas y ficticias. En nada comparables con anteriores formas de identificación como las clases y la militancia política, así como con formas de sociabilidad resistentes a ser integradas y homogenizadas culturalmente como las llamadas minorías étnicas.

Ahora bien, es necesario distinguir entre la critica realizada por Adorno y Marcuse a la cultura de masas y la supuesta actitud de los miembros de la Escuela de Frankfurt a favor de una cultura elitista, o de cierta concepción despectiva, frente a los hombres que se hallan reunidos en masa. No hay nada en este sentido que pudiera asemejar el pensamiento de Adorno con el pensamiento de filósofos como Nietzsche y Ortega y Gasset, quienes veían en la masa la decadencia y disolución de los valores más elevados de la civilización (Ortega y Gasset, 1970). Por el contrario, Adorno nos advierte que en tal desprecio a las masas se ocultan, claramente, intenciones ideológicas, en las cuales, en lugar de permitirse captar

\footnotetext{
${ }_{13}$ Por formas de sociabilidad entendemos aquí las maneras en las que se establecen vínculos, lazos e identidades entre los seres humanos, estas sociabilidades ciertamente no se reducen a relaciones de intercambio, pero a menudo son amenazadas en la lógica de acumulación del capital, en los procesos de explotación del trabajo y de cosificación de las diversas esferas de la vida social, tendiendo a quedar convertidas en simples relaciones de interés.
} 
las causas por las que la demagogia utilizada en los regímenes autoritarios puede cohesionar y manipular a una multitud de hombres, sirve como pretexto para que los hombres agrupados en masa sean objeto de tales controles (1969, p. 88). Como lo expresa Adorno: "Freud logra dilucidar más claramente que Le Bon los factores y condiciones por las que unos hombres renuncian a parte de su individualidad y se vinculan a una masa, cuando lo explica por factores psicológicos que cuando Le Bon lo hace a través de misteriosas cualidades inherentes a la masa, como la llamada "alma de la masa"" (89).

La cita aludida nos permite realizar una interpretación diferente del pensamiento de Adorno. Una interpretación en la que aparece muy alejado del supuesto elitismo cultural, adjudicado, incluso, por biógrafos de la Escuela de Frankfurt como Martin Jay (1974). Entonces, la tesis que defendemos intenta deslindar la crítica a la cultura de masas llevada a cabo por Adorno y su supuesta actitud de desprecio hacia los hombres reunidos en masa.

Tal como se evidenció, Adorno indica que quienes constituyen una masa difícilmente se sienten pertenecientes a ésta, de ahí que "raramente alguien acepte considerarse como hombre masa; la masa son siempre los otros" (1969, p. 77). Por esta razón, autores como Martín Barbero (1998) yerran, cuando acusan a Adorno de tener una valoración negativa de lo que significa la vida de los hombres que se agrupan dentro de una masa. En esto permanecería Adorno fiel al pensamiento de Marx, quien seguramente idealizó, por sus mismas circunstancias históricas, el potencial revolucionario de la masa obrera.

En concordancia con lo expuesto, el análisis realizado de los procesos de integración del individuo a la sociedad indica que la eficiencia de control y manipulación no está sujeta a la incorporación del individuo a una masa o agrupación. La misma noción de cultura de masas puede ser equívoca si se toma sólo como la difusión de la actividad cultural en espacios masivos o colectivos. Así, la televisión, la radio y el internet prueban que los medios masivos pueden difundir su publicidad en espacios privados, conservando su carácter accesible a las masas. Hoy podemos decir que, más que antes, los hombres nunca estuvieron tan cercanos y concentrados en un mismo espacio, como en los centros comerciales y los sistemas de transporte masivo de todo el mundo, así como ahora existe la posibilidad de estar al mismo tiempo tan atomizados, dispersos y despolitizados en la "sociedad". Según esta observación, se puede decir que la crisis de representación en nuestra sociedad, los límites de los referentes constituyentes de identidad y creadores de comunidad, como la religión, los partidos políticos y las organizaciones sociales, en vez de acabar con la cultura de masas, terminan, en realidad, fortaleciéndola. Ahora, el consumo parece remplazar la función de creación de identidad y de sociabilidad cumplida, en otras épocas, por las costumbres, las tradiciones, las ideas políticas, o la pertenencia a una comunidad. Esta última forma de identidad y sociabilidad basada en el consumo, tendría 
actualmente mayores posibilidades de universalización con las capacidades de comunicación ofrecidas a través del internet, la telefonía celular y la televisión. Posibilidades que en el caso de la mayoría de las denominadas redes sociales en el Internet se manifiestan, sobre todo, con la superficialidad y banalidad de sus contenidos $\Phi$

\section{REFERENCIAS}

Adorno, T. (1969). "La industria cultural". La Industria Cultural. Buenos Aires: Galerna.

Adorno, T. (1972). Filosofía y superstición. Madrid: Taurus.

Blesa, P. (2006). "Medios de comunicación y democracia: ¿El poder de los medios o los medios al poder?" Revista Sphera Pùblica. Número 6. pp. 87-106.

Entel, A. (2001). Acerca de la felicidad: Un análisis de tres escritos de Herbert Marcuse. Buenos Aires: Prometeo.

Freud, S. (1997). "Los dos principios del acaecer psíquico". Obras completas. Buenos Aires: Biblioteca Nueva.

Hobbes, T. (1999). El Leviatán. Madrid: Alianza.

Horkheimer, M. y Adorno, T. (1969a). Dialéctica del iluminismo. Buenos Aires: Sur.

Horkheimer, M. y Adorno, T. (1969b). La sociedad: Lecciones de sociología. Buenos Aires: Proteo.

Guerra, F. (1992). Modernidad e independencias. Ensayos sobre las revoluciones hispánicas. Madrid: Mapfre.

Jay, M. (1974). La Imaginación dialéctica. Una historia de la escuela de Frankfurt. Madrid: Taurus.

Kant, E. (1986). "Respuesta a la pregunta ¿Qué es la ilustración?" Revista Argumentos. Número 16. pp. 45-76.

Locke, J. (2006). Segundo tratado sobre el gobierno civil. Madrid: Tecnos.

Marcuse, H. (1967). "Acerca del carácter afirmativo de la cultura". Cultura y sociedad. Buenos Aires: Sur. 

aproximación desde la teoría crítica de la sociedad

Marcuse, H. (1974). "El envejecimiento del psicoanálisis". Sexualidad y represión. Buenos Aires: Escuela Talcahuano.

Marcuse, H. (1979). La agresividad en la sociedad industrial avanzada. Madrid: Alianza.

Marcuse, H. (1995). El hombre unidimensional. Barcelona: Planeta-Agostini.

Marcurse, H. (2003). Eros y civilización. Barcelona: Ariel.

Martin Barbero, J. (1998). De los medios a las mediaciones. Bogotá: Convenio Andrés Bello.

Marx, K. (2008). La ideología alemana. Valencia: Universitat Valencia.

Muñoz, B. (2000). Adorno Theodor: Teoría crítica y cultura de masas. Madrid: Fundamentos.

Ortega y Gasset, J. (1970). La Rebelión de las Masas. Madrid: Espasa Calpe.

Rousseau, J. J. (1998). El origen de las desigualdades entre los hombres. México. Fondo de Cultura Económica. 